\title{
Phase II Study of Gemcitabine and Docetaxel Combination in Patients with Previously Treated Recurrent or Metastatic Squamous Cell Carcinoma of the Head and Neck
}

\author{
Zyad Kafri, ${ }^{1,2}$ Lance K. Heilbrun, ${ }^{1}$ Ammar Sukari, ${ }^{1}$ George Yoo, ${ }^{1}$ John Jacobs, ${ }^{1}$ \\ Ho-Sheng Lin, ${ }^{1}$ Heather Mulrenan, ${ }^{1}$ Daryn Smith, ${ }^{1}$ and Omer Kucuk ${ }^{1}$ \\ ${ }^{1}$ Barbara Ann Karmanos Cancer Institutte, Wayne State University School of Medicine, Detroit, MI 48201, USA \\ ${ }^{2}$ Division of Hematology/Oncology, St. John Hospital, Wayne State University School of Medicine, 19229 Mack Avenue, \\ Grosse Pointe Woods, Detroit, MI 48236, USA
}

Correspondence should be addressed to Zyad Kafri, zyad.kafri@stjohn.org

Received 1 January 2012; Accepted 22 January 2012

Academic Editors: M. Emoto and M. Santarosa

Copyright ( 2012 Zyad Kafri et al. This is an open access article distributed under the Creative Commons Attribution License, which permits unrestricted use, distribution, and reproduction in any medium, provided the original work is properly cited.

Purpose. To explore the safety and efficacy of gemcitabine and docetaxel (GEMDOC) in previously treated patients with recurrent or metastatic squamous cell carcinoma of the head and neck (SCCHN). Patients and Methods. Patients with advanced SCCHN previously pretreated with one or two lines of palliative chemotherapy were treated with gemcitabine and docetaxel until disease progression. Results. Thirty-six patients were enrolled, and 29 were response evaluable. 16 (55\%) experienced clinical benefit (response or stable disease). Six (21\%) patients achieved partial response (PR), none achieved complete response (CR), and the overall response rate (ORR) was $21 \%$ (95\% CI: $0.10-0.38)$. Ten (28\%) patients had stable disease. The median response duration (RD) for the 6 PR patients was 3.2 months (80\% CI: 2.0-6.1 months). Median overall survival was 4.2 months (95\% CI: $2.4-$ 7.0 months). Among the 33 treated patients: 13 (39\%) patients had grade 3-4 anemia, 10 (30\%) had grade 3-4 neutropenia. Conclusion. The study drugs were relatively safe, and the clinical benefit (PR + SD) rate was 55\%. However, the efficacy objective for this regimen was not met. Given the good safety profile, further investigation of this regimen with the addition of a targeted agent may lead to better efficacy.

\section{Introduction}

Patients with squamous cell carcinoma of head and neck (SCCHN) who had disease recurrence after primary surgery or chemoradiation therapy or who present with metastatic disease usually have a poor prognosis [1]. The role of chemotherapy in this setting is palliative, complete response is rare, and duration of response is short.

Single-agent docetaxel was previously evaluated in four phase II studies involving approximately 160 patients with metastatic or recurrent SCCHN. The overall response rates observed in these studies ranged from $21 \%$ to $42 \%$ [2-5]. The principal toxicity reported in these studies was grade 3 and 4 neutropenia. Based on these phase II studies, singleagent docetaxel $75-100 \mathrm{mg} / \mathrm{m}^{2}$ IV every 3 weeks was shown to be an active and generally well-tolerated regimen for metastatic or recurrent SCCHN.

Docetaxel has also been evaluated as part of a doublet in combination with cisplatin or 5-fluorouracil (5-FU) in patients with recurrent or metastatic SCCHN. In phase I/II trials evaluating the combination of docetaxel and cisplatin the overall response rates were $33 \%$ to $40 \%$ [6-8]. Studies evaluating the combination of docetaxel and 5-FU yielded response rates from $24 \%$ to $27 \%[9,10]$. Of the two doublets, docetaxel combined with cisplatin appeared to be the more effective regimen in regard to both objective and complete responses [6-9]. In a phase II study conducted by EORTC, the response rate to the docetaxel plus cisplatin arm was $86 \%$ in patients with chemotherapy and radiation naïve disease versus $33 \%$ for the pretreated group [7]. As with 
TABLE 1: Phase II studies of biweekly gemcitabine and docetaxel (GEMDOC).

\begin{tabular}{|c|c|c|c|c|}
\hline Author & $N$ & Tumor type & Treatment regimen & Toxicity \\
\hline Galetta et al. [11] & 45 & NSCLC & $\begin{array}{l}\text { Gemcitabine } 2000 \mathrm{mg} / \mathrm{m}^{2} \mathrm{q} 2 \text { weeks } \\
\text { and docetaxel } 50 \mathrm{mg} / \mathrm{m}^{2}\end{array}$ & $\begin{array}{l}\text { Grade } 3 \text { and } 4 \text { neutropenia 23\%, } \\
\text { Grade } 3 \text { and } 4 \text { alopecia } 34 \%\end{array}$ \\
\hline Pelegri et al. [12] & 36 & Breast cancer & $\begin{array}{l}\text { Gemcitabine } 2500 \mathrm{mg} / \mathrm{m}^{2} \mathrm{q} 2 \text { weeks } \\
\text { and docetaxel } 65 \mathrm{mg} / \mathrm{m}^{2}\end{array}$ & Grade 3 and 4 neutropenia 45\% \\
\hline Syrigos et al. [13] & 25 & NSCLC & $\begin{array}{l}\text { Gemcitabine } 1000 \mathrm{mg} / \mathrm{m}^{2} \mathrm{q} 2 \text { weeks } \\
\text { and docetaxel } 80 \mathrm{mg} / \mathrm{m}^{2}\end{array}$ & $\begin{array}{l}\text { Anemia } 16 \% \text {, neutropenia } 20 \% \text {, febrile } \\
\text { neutropenia } 10 \% \text {, diarrhea } 24 \% \text {, and } \\
\text { asthenia } 64 \%\end{array}$ \\
\hline Shepard et al. [14] & 32 & Pancreatic & $\begin{array}{l}\text { Gemcitabine } 2000 \mathrm{mg} / \mathrm{m}^{2} \mathrm{q} 2 \text { weeks } \\
\text { and docetaxel } 75 \mathrm{mg} / \mathrm{m}^{2}\end{array}$ & $\begin{array}{l}\text { No grade } 4 \text { toxicity } \\
\text { Grade } 3 \text { neutropenia } 31 \%\end{array}$ \\
\hline
\end{tabular}

single-agent docetaxel, the primary toxicity in each series was myelosuppression.

Gemcitabine has shown significant activity in a wide variety of solid tumors, including cancers of pancreas [15], breast [16], lung [17], and ovary [18]. A trial of gemcitabine in head and neck cancers used a relatively low dose $\left(800 \mathrm{mg} / \mathrm{m}^{2}\right)$ and reported 7 partial responses $(11 \%)$ in 62 patients [19]. Multiple investigators have evaluated the combination of gemcitabine and docetaxel (GEMDOC) in phase II clinical trials on biweekly bases. [11-14] Previous phase II studies of biweekly GEMDOC have included patients with non-small-cell lung cancer, breast cancer, and pancreatic cancer and are summarized in Table 1. The doses that we selected from our previous phase I/II trials experience in head and neck cancer at our facility were $3000 \mathrm{mg} / \mathrm{m}^{2}$ for gemcitabine and $60 \mathrm{mg} / \mathrm{m}^{2}$ for docetaxel.

The biweekly GEMDOC combination is an attractive regimen in the treatment of advanced head and neck cancer since both agents are active against SCCHN with a low toxicity profile. Therefore, we conducted this phase II clinical trial to explore the efficacy and toxicity of the GEMDOC combination given biweekly for patients previously treated with recurrent or metastatic SCCHN.

\section{Patients and Methods}

2.1. Patients. Patients with recurrent or metastatic histologically proven SCCHN who had received 1 to no more than 2 prior chemotherapy regimens were eligible. Patients who received a prior taxane agent or gemcitabine were not eligible. Patients were required to have at least one bidimensional measurable disease site, assessed by radiologic exam performed and documented within 28 days prior to registration. Additional eligibility criteria included a treatment-free interval of at least 4 weeks prior to study entry, and no CNS metastases. Patients must have had a SWOG performance status of $\leq 2$, adequate hematologic cell counts (absolute neutrophil count $\geq 1,500 / \mu \mathrm{L}$ and platelets $\geq 100,000 / \mu \mathrm{L}$ ), and adequate liver and renal function.

The institutional review board of the participating center approved the study, and all patients provided signed informed consent.

2.2. Study Design and Treatment. This was a prospective, phase II evaluation of biweekly doses of gemcitabine and docetaxel. Treatment was given as gemcitabine $3000 \mathrm{mg} / \mathrm{m}^{2}$ IV over 30 minutes followed by docetaxel $60 \mathrm{mg} / \mathrm{m}^{2} \mathrm{IV}$ over 60 minutes. Appropriate antiemetics were used as premedication as well as dexamethasone, either $8 \mathrm{mg} \mathrm{PO}$ BID starting one day before each dose of docetaxel for 3 days or as $20 \mathrm{mg}$ IV prior to docetaxel infusion [20]. Treatment was repeated every two weeks with appropriate dose modifications until disease progression, unacceptable toxicity, or complete remission plus 4 cycles, whichever occurred first. Patients continued to receive treatments in the absence of any grade 2 or higher toxicities. Infusion was given on day 1 of treatment with the appropriate dose adjustment if absolute neutrophil count was $>1,000 / \mu \mathrm{L}$ and platelet count was $>50,000 / \mu \mathrm{L}$. Treatment delay and dose reductions for docetaxel and gemcitabine were implemented for grade 3-4 neutropenia, thrombocytopenia, or liver dysfunction. Patients who failed to achieve hematologic recovery for 3 consecutive weeks or more than 4 weeks for nonhematologic toxicities were removed from the study.

2.3. On-Study Evaluation. Tumor response was assessed radiographically with standard methods using RECIST criteria [21] every 4 cycles (approximately 2 months). Toxicity was evaluated before each cycle. All patients were considered (regardless of the number of cycles they received) evaluable for response.

The best overall response was the best response that was recorded from the start of treatment until disease progression. The duration of response was measured from the time measurement criteria were met for complete response (CR) or partial response (PR) (whichever status was recorded first) until the first date that recurrence or progressive disease (PD) was recorded since the treatment started. Duration of stable disease (SD) was measured from the start of treatment until the criteria for disease progression were met. Responseevaluable patients were those who were registered and had their response evaluated and determined by appropriate measurements, regardless of the number of chemotherapy cycles they received. Toxicity-evaluable patients were those who received chemotherapy or any portion of a cycle of therapy. Patients were taken off the study if they had documented PD, an unacceptable adverse event, patient decision to withdraw from the study, investigator judgment to stop treatment, or upon completion of 4 cycles after first documented CR. 
TABle 2: Baseline characteristics and clinical variables for all 36 patients.

\begin{tabular}{lc}
\hline Characteristic & $N(\%)$ \\
\hline Age (years) & $60(46-79)$ \\
$\quad$ Median (range) & \\
Sex & $10(28 \%)$ \\
$\quad$ Female & $26(72 \%)$ \\
$\quad$ Male & \\
Race & $22(61 \%)$ \\
Caucasian & $12(33 \%)$ \\
African-American & $2(5 \%)$ \\
Other & \\
Performance status (ECOG) & $8(22 \%)$ \\
0 & $26(72 \%)$ \\
1 & $2(6 \%)$ \\
2 & \\
Prior chemo-radiotherapy & $1(3 \%)$ \\
No & $35(97 \%)$ \\
Yes & \\
Sites of metastasis & $21(58 \%)$ \\
Lung & $2(6 \%)$ \\
Liver & $6(17 \%)$ \\
Other & \\
Meatment cycles administered & \\
\hline Perange) & \\
\hline
\end{tabular}

Percentages may not sum up to 100 due to rounding.

Multiple sites of metastasis may have occurred in the same patient.

The safety and tolerability of biweekly docetaxel and gemcitabine were evaluated by clinical laboratory assessments, physical examination, and the frequency and severity of adverse events. Complete blood counts and serum biochemical assessments were performed every 2 weeks throughout the study. The severity of adverse events was graded according to the Common Toxicity Criteria Version 2.0 of the National Cancer Institute. Serious adverse events included grade 3-4 hematologic and nonhematologic toxicities. Concurrent illnesses, infections, blood product support, and antimicrobial therapies were monitored.

2.4. Statistical Methods. This single-institution phase II trial was planned with a Simon two-stage optimal design [22]. The primary endpoint was complete or partial response (CR $+\mathrm{PR})$. We wished to distinguish these regions of the true, unknown response rate: at most 0.25 versus at least 0.45 . The 2-stage design called for a maximum of 41 responseevaluable (r-e) patients, 17 in stage 1 and 24 in stage 2 . The design had a type I error of 0.050 and power of 0.803 .

For response and toxicity rates, Wilson type $95 \%$ confidence intervals (CI) were calculated. Response duration (RD) was measured from start of best response until relapse. Patients still in remission were censored as of the date of their last tumor assessment. Due to the small number of responders $(n=6)$, the $80 \%$ confidence level was used for the CI of RD. Time to treatment failure (TTF) was measured from registration until early discontinuation of treatment, first observation of progressive disease, or death from any cause, whichever occurred first. Patients still on treatment were censored as of the date of their last tumor assessment. Time to progression (TTP) was measured from registration until the date of documented progressive disease. Patients still progression-free were censored as of the date of their last tumor assessment. Overall survival (OS) was measured from registration to the date of death from any cause. Patients still alive were censored as of the most recent date on which they were known to be alive. Standard Kaplan-Meier estimates of the censored RD, TTF, TTP, and OS distributions were computed. Due to the small sample sizes, survival statistics (e.g., median, 6 month rate, etc.) were estimated more conservatively using linear interpolation among successive event times on the Kaplan-Meier curves [23].

\section{Results}

3.1. Patient Demographics and Disposition. Thirty-six patients were enrolled between May 2005 and May 2008. Median age was 60 years (range: 46 to 79 years) (Table 2). Ten female patients (28\%) enrolled. $94 \%$ of the patients had good performance status (0-1). Patients with prior chemo-radiotherapy were $97 \%$. The most common site of distant metastasis was lung, in $58 \%$ of the patients. The median number of cycles administered was 4 (range: 0 to 24 cycles). Three patients were registered for the study but did not receive any chemotherapy or follow up staging studies; therefore, they are considered neither r-e nor drug toxicity evaluable. In addition, 4 other patients were considered not r-e due to lack of follow-up staging studies to assess response.

3.2. Treatment Efficacy. Patient accrual continued to stage 2 of the study design based on the acceptable safety profile, but mainly to help define the true response rate, which appeared to be lower than predicted. Of the $29 \mathrm{r}$-e patients, 16 (55\%) experienced clinical benefit (SD or disease response). Six (21\%) patients achieved PR, no patients achieved CR, and the overall response rate (ORR) was $21 \%$ (95\% CI: 0.10 0.38 ; Table 3). In an intent-to-treat analysis of all 36 patients enrolled, the ORR was $17 \%$ (95\% CI: $0.08-0.32$ ). Ten (28\%) patients had SD. The median $\mathrm{RD}$ for the 6 responding patients was 3.2 months ( $80 \%$ CI: 2-6.1).

3.3. Hematologic Toxicity. Biweekly gemcitabine and docetaxel (GEMDOC) was generally well tolerated (Table 3 ). There were no treatment-related deaths. Bone marrow suppression was the main toxicity. Thirteen $(39 \%)$ of the 33 treated patients had grade 3-4 anemia, and $10(30 \%)$ patients had grade 3-4 neutropenia. Grade 3-4 thrombocytopenia occurred in only $2(6 \%)$ patients. Only one patient had febrile neutropenia.

Twenty-five (76\%) patients received all treatments without a dose reduction and twenty-seven $(82 \%)$ patients had no treatment interruption. 
TABLE 3: Grade 3-4 toxicity summary statistics for all 33 treated patients.

\begin{tabular}{|c|c|c|c|c|c|}
\hline Grade 3-4 toxicity & $N$ & Events & $\begin{array}{c}\text { Point } \\
\text { estimate }\end{array}$ & \multicolumn{2}{|c|}{$95 \%$ confidence interval } \\
\hline Anemia & 33 & 13 & $39 \%$ & $25 \%$ & $56 \%$ \\
\hline Neutropenia & 33 & 10 & $30 \%$ & $17 \%$ & $47 \%$ \\
\hline Hyponatremia & 33 & 10 & $30 \%$ & $17 \%$ & $47 \%$ \\
\hline Dehydration & 33 & 3 & $9 \%$ & $3 \%$ & $24 \%$ \\
\hline Fatigue & 33 & 3 & $9 \%$ & $3 \%$ & $24 \%$ \\
\hline Dyspnea & 33 & 3 & $9 \%$ & $3 \%$ & $24 \%$ \\
\hline Pneumonia & 33 & 3 & $9 \%$ & $3 \%$ & $24 \%$ \\
\hline Thrombocytopenia & 33 & 2 & $6 \%$ & $2 \%$ & $20 \%$ \\
\hline Febrile neutropenia & 33 & 1 & $3 \%$ & $1 \%$ & $15 \%$ \\
\hline Tachycardia & 33 & 1 & $3 \%$ & $1 \%$ & $15 \%$ \\
\hline Syncope & 33 & 1 & $3 \%$ & $1 \%$ & $15 \%$ \\
\hline Fluid retention & 33 & 1 & $3 \%$ & $1 \%$ & $15 \%$ \\
\hline Mucositis & 33 & 1 & $3 \%$ & $1 \%$ & $15 \%$ \\
\hline Hyperglycemia & 33 & 1 & $3 \%$ & $1 \%$ & $15 \%$ \\
\hline Constipation & 33 & 1 & $3 \%$ & $1 \%$ & $15 \%$ \\
\hline Anorexia & 33 & 1 & $3 \%$ & $1 \%$ & $15 \%$ \\
\hline Vomiting & 33 & 1 & $3 \%$ & $1 \%$ & $15 \%$ \\
\hline Other nonhematologic toxicity & 33 & 1 & $3 \%$ & $1 \%$ & $15 \%$ \\
\hline
\end{tabular}

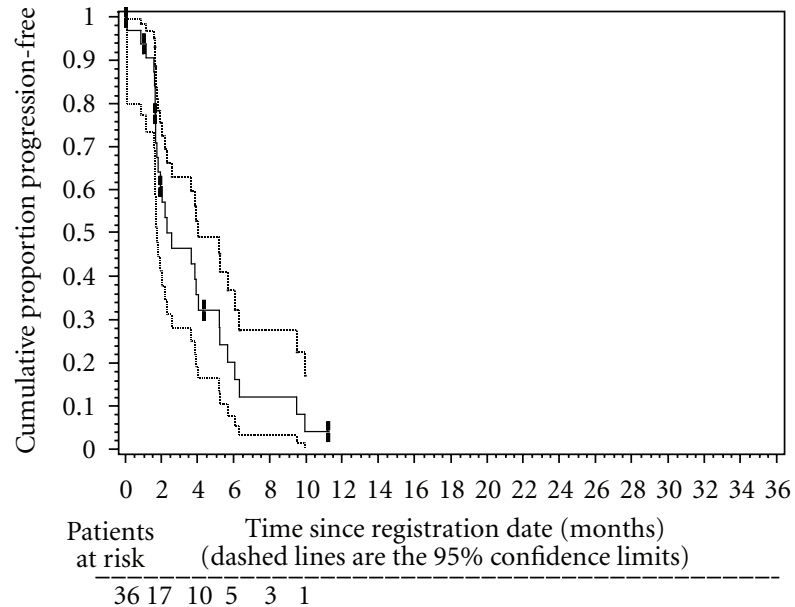

FIGURE 1: Kaplan-Meier plot of time to progression (TTP) in 36 patients treated with biweekly gemcitabine and docetaxel. Median TTP was 2.3 months (95\% CI: 1.5-3.8 months). The 3-month TTP rate was $45 \%$ (95\% CI: $27-63 \%)$. The 6 -month TTP rate was $17 \%$ (95\% CI: $1-32 \%)$.

3.4. Nonhematologic Toxicity. The most common grade 34 nonhematologic adverse event was hyponatremia, which occurred in 10 (30\%) patients (Table 3). Grade 3-4 fatigue, dehydration, and dyspnea occurred in 3 (9\%) patients for each toxicity. Of note, there were no reports of grade 3-4 neuropathy.

3.5. Time to Treatment Failure, Time to Progression, and Overall Survival. The median TTF was 2.0 months (95\% CI:

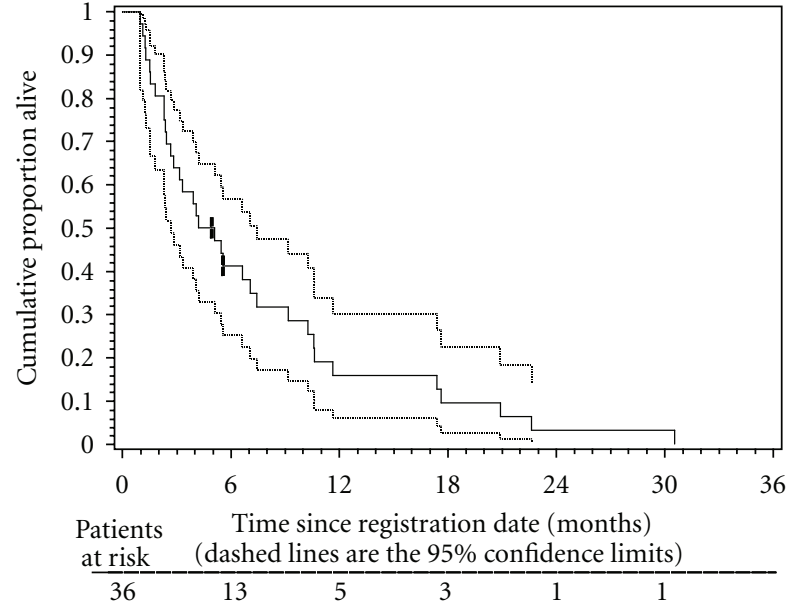

FIGURE 2: Kaplan-Meier plot of overall survival (OS) in 36 patients treated with biweekly gemcitabine and docetaxel. Median OS was 4.2 months (95\% CI: 2.4-7.0 months). The 6-month OS rate was $40 \%$ (95\% CI: $24-56 \%$ ). The 12 -month OS rate was $16 \%$ (95\% CI: $3-28 \%)$.

1.6 to 3.6$)$, and the median TTP was 2.3 months (95\% CI: 1.5-3.8; Figure 1). The median OS was 4.2 months (95\% CI =2.4-7.0; Figure 2).

\section{Discussion}

In this single-institution phase II trial, patients with recurrent or metastatic SCCHN were treated with the biweekly combination of gemcitabine and docetaxel (GEMDOC) after 
the failure of at least one prior chemotherapy regimen. Of the 29 response evaluable patients only 6 achieved PR and there was no CR observed. It was concluded that the sample response rate among the $\mathrm{r}$-e patients $(6 / 29=21 \%)$ better supported the null hypothesis that the true, unknown response rate was at most $25 \%$. However, the clinical benefit $(\mathrm{PR}+\mathrm{SD})$ rate was $55 \%$. One proposed reason for the low response rate is the type of recurrent disease treated, as the majority of patients included in this trail had previous one to two lines of chemotherapy or concurrent chemoirradiation with unresectable relapses in the radiation field. The study design excluded metastatic-chemotherapy-naïve patients. Median response duration in the 6 responders was 3.2 months. Median time to treatment failure was 2.0 months, with median survival of 4.2 months (Figure 2).

Biweekly treatment with gemcitabine and docetaxel was generally well tolerated. The median number of cycles administered was 4 . Bone marrow suppression was the main toxicity. Ten (30\%) patients had grade 3-4 neutropenia, 25 $(76 \%)$ patients received all treatments without a dose reduction, and $27(82 \%)$ patients had no treatment interruption. This trial explored a new potential treatment option in a bad prognosis group of patients with metastatic or recurrent SCCHN.

Although the studied treatment regimen was safe, the response rate was lower than predicted and the study was terminated. Docetaxel is a well-established agent in the treatment of SCCHN $[6-8,24]$, and probably there was more added efficacy by combing it with gemcitabine.

Recent data in recurrent or metastatic SCCHN showed better treatment efficacy driven from combination chemotherapy with cisplatin, 5-fluorouracil, and cetuximab [25]. Future clinical trials in this setting should be based on the use of doublets, either platinum based or taxane based, with a targeted agent. Given the good safety profile and the overall clinical benefit of the biweekly GEMDOC regimen, further investigation of this combination with the addition of targeted agents may lead to better efficacy results.

\section{Acknowledgments}

This study was sponsored by a grant from Eli Lilly and Sanofi-Aventis pharmaceuticals. Also, it was partially supported by the NIH Karmanos Cancer Institute core grant CA22453.

\section{References}

[1] G. L. Clayman, S. M. Lippman, G. E. Laramore, and W. K. Hong, "Head and neck cancer," Cancer Medicine, pp. 1645$1710,1997$.

[2] A. I. Dreyfuss, J. R. Clark, C. M. Norris et al., "Docetaxel: an active drug for squamous cell carcinoma of the head and neck," Journal of Clinical Oncology, vol. 14, no. 5, pp. 16721678, 1996.

[3] G. Catimel, J. Verweij, V. Mattijssen et al., "Docetaxel (Taxotere): an active drug for the treatment of patients with advanced squamous cell carcinoma of the head and neck," Annals of Oncology, vol. 5, no. 6, pp. 533-537, 1994.
[4] C. Couteau, N. Chouaki, S. Leyvraz et al., "A phase II study of docetaxel in patients wtth metastatic squamous cell carcinoma of the head and neck," British Journal of Cancer, vol. 81, no. 3, pp. 457-462, 1999.

[5] Y. Inuyama, A. Kataura, K. Togawa et al., "Late phase II clinical study of RP56976 (docetaxel) in patients with advanced/recurrent head and neck cancer," Gan To Kagaku Ryoho, vol. 26, no. 1, pp. 107-116, 1999.

[6] B. S. Glisson, B. A. Murphy, G. Frenette, F. R. Khuri, and A. A. Forastiere, "Phase II trial of docetaxel and cisplatin combination chemotherapy in patients with squamous cell carcinoma of the head and neck," Journal of Clinical Oncology, vol. 20, no. 6, pp. 1593-1599, 2002.

[7] P. Schoffski, G. Catimel, A. S. T. Planting et al., "Docetaxel and cisplatin: an active regimen in patients with locally advanced, recurrent or metastatic squamous cell carcinoma of the head and neck: results of a phase II study of the EORTC Early Clinical Studies Group," Annals of Oncology, vol. 10, no. 1, pp. 119-122, 1999.

[8] L. Specht, S. K. Larsen, and H. S. Hansen, "Phase II study of docetaxel and cisplatin in patients with recurrent or disseminated squamous-cell carcinoma of the head and neck," Annals of Oncology, vol. 11, no. 7, pp. 845-849, 2000.

[9] A. D. Colevas, S. Adak, P. C. Amrein, J. J. Barton, R. Costello, and M. R. Posner, "A phase II trial of palliative docetaxel plus 5-fluorouracil for squamous-cell cancer of the head and neck," Annals of Oncology, vol. 11, no. 5, pp. 535-539, 2000.

[10] D. Genet, D. Cupissol, N. Tubiana-Mathieu et al., "Docetaxel plus 5-fluorouracil in locally recurrent and/or metastatic squamous cell carcinoma of the head and neck: a phase II multicenter study," American Journal of Clinical Oncology, vol. 27, no. 5, pp. 472-476, 2004.

[11] D. Galetta, V. Gebbia, F. Giotta et al., "Gemcitabine and docetaxel every 2 weeks in advanced non-small cell lung cancer: a phase II study of the Gruppo Oncologico Italia Meridionale," Lung Cancer, vol. 38, no. 1, pp. 79-84, 2002.

[12] A. Pelegri, L. Calvo, J. Florian et al., "Every other week combination of gemcitabine and docetaxel as first line therapy in advanced breast cancer patients: preliminary results from a phase II trial," Breast Cancer Research and Treatment, vol. 69, pp. 270-356, 2001.

[13] K. Syrigos, E. Karapanagiotou, A. Charpidou et al., "Biweekly administration of docetaxel and gemcitabine for elderly patients with advanced non-small cell lung cancer: a phase II study," Journal of Chemotherapy, vol. 19, no. 4, pp. 438-443, 2007.

[14] R. C. Shepard, D. Levy, J. D. Berlin et al., "Phase II study of gemcitabine in combination with docetaxel in patients with advanced pancreatic carcinoma (E1298): a trial of the Eastern Cooperative Oncology Group," Oncology, vol. 66, no. 4, pp. 303-309, 2004.

[15] E. S. Casper, M. R. Green, D. P. Kelsen et al., "Phase II trial of gemcitabine (2,2'-difluorodeoxycytidine) in patients with adenocarcinoma of the pancreas," Investigational New Drugs, vol. 12, no. 1, pp. 29-34, 1994.

[16] J. Carmichael, K. Possinger, P. Phillip et al., "Advanced breast cancer: a phase II trial with gemcitabine," Journal of Clinical Oncology, vol. 13, no. 11, pp. 2731-2736, 1995.

[17] J. B. Sorensen, "Gemcitabine in non-small cell lung cancer," Lung Cancer, vol. 12, no. 1, pp. S173-S175, 1995.

[18] B. Lund, O. P. Hansen, K. Theilade, M. Hansen, and J. P. Neijt, "Phase II study of gemcitabine $\left(2^{\prime}, 2^{\prime}\right.$-difluorodeoxycytidine) in previously treated ovarian cancer patients," Journal of the National Cancer Institute, vol. 86, no. 20, pp. 1530-1533, 1994. 
[19] G. Catimel, J. B. Vermorken, M. Clavel et al., "A phase II study of Gemcitabine (LY 188011) in patients with advanced squamous cell carcinoma of the head and neck," Annals of Oncology, vol. 5, no. 6, pp. 543-547, 1994.

[20] C. N. Rittenberg, R. J. Gralla, and J. T. Cole, "Preventing docetaxel induced fluid retention: the efficacy of corticosteroids," in Proceedings of the American Society of Clinical Oncology (ASCO '96), vol. 15, p. 531, 1996.

[21] P. Therasse, S. G. Arbuck, E. A. Eisenhauer et al., "New guidelines to evaluate the response to treatment in solid tumors," Journal of the National Cancer Institute, vol. 92, no. 3, pp. 205-216, 2000.

[22] R. Simon, "Optimal two-stage designs for phase II clinical trials," Controlled Clinical Trials, vol. 10, no. 1, pp. 1-10, 1989.

[23] E. Lee and J. W. Wang, Statistical Methods for Survival Data Analysis, John Wiley \& Sons, New York, NY, USA, 3rd edition, 2003.

[24] M. R. Posner, D. M. Hershock, C. R. Blajman et al., "Cisplatin and fluorouracil alone or with docetaxel in head and neck cancer," The New England Journal of Medicine, vol. 357, no. 17, pp. 1705-1715, 2007.

[25] J. B. Vermorken, R. Mesia, F. Rivera et al., "Platinum-based chemotherapy plus cetuximab in head and neck cancer," The New England Journal of Medicine, vol. 359, no. 11, pp. 11161127, 2008. 


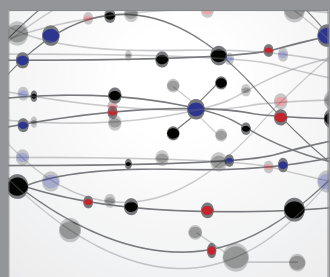

The Scientific World Journal
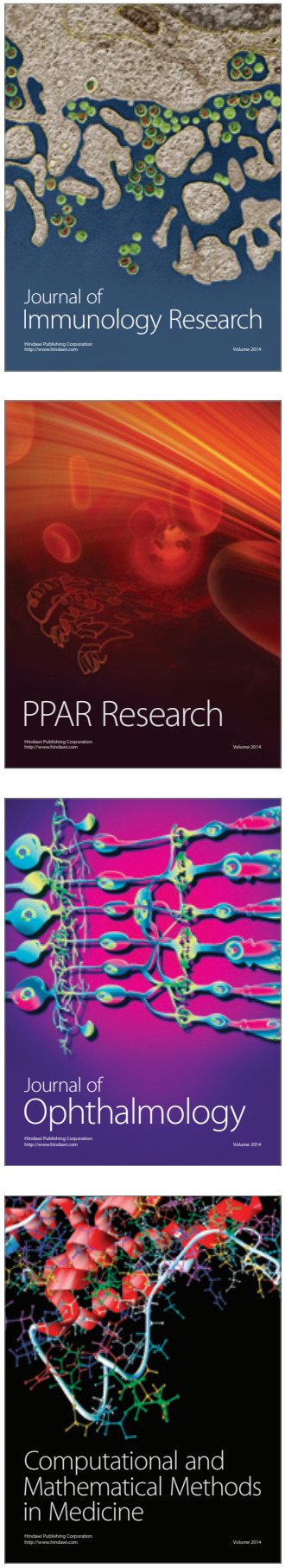

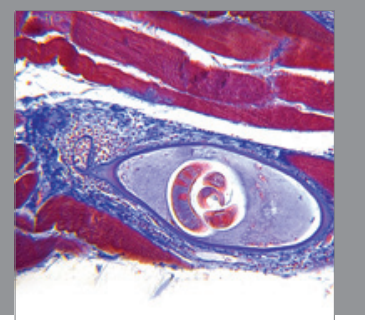

Gastroenterology

Research and Practice
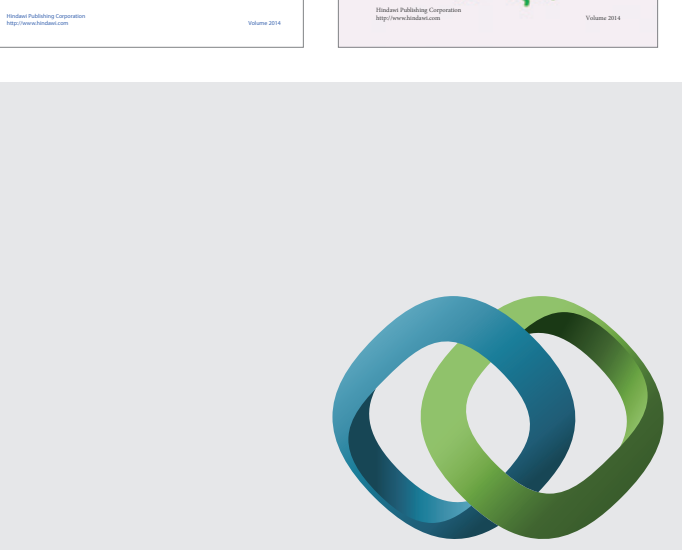

\section{Hindawi}

Submit your manuscripts at

http://www.hindawi.com
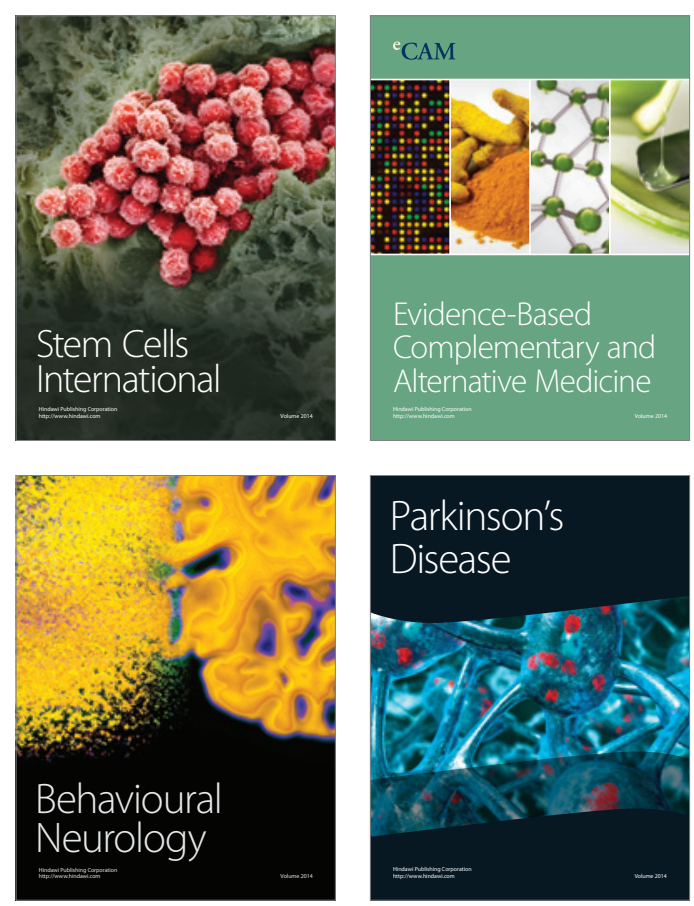

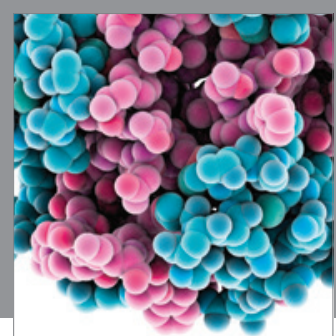

Journal of
Diabetes Research

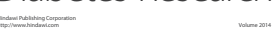

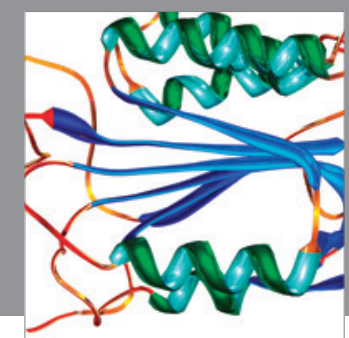

Disease Markers
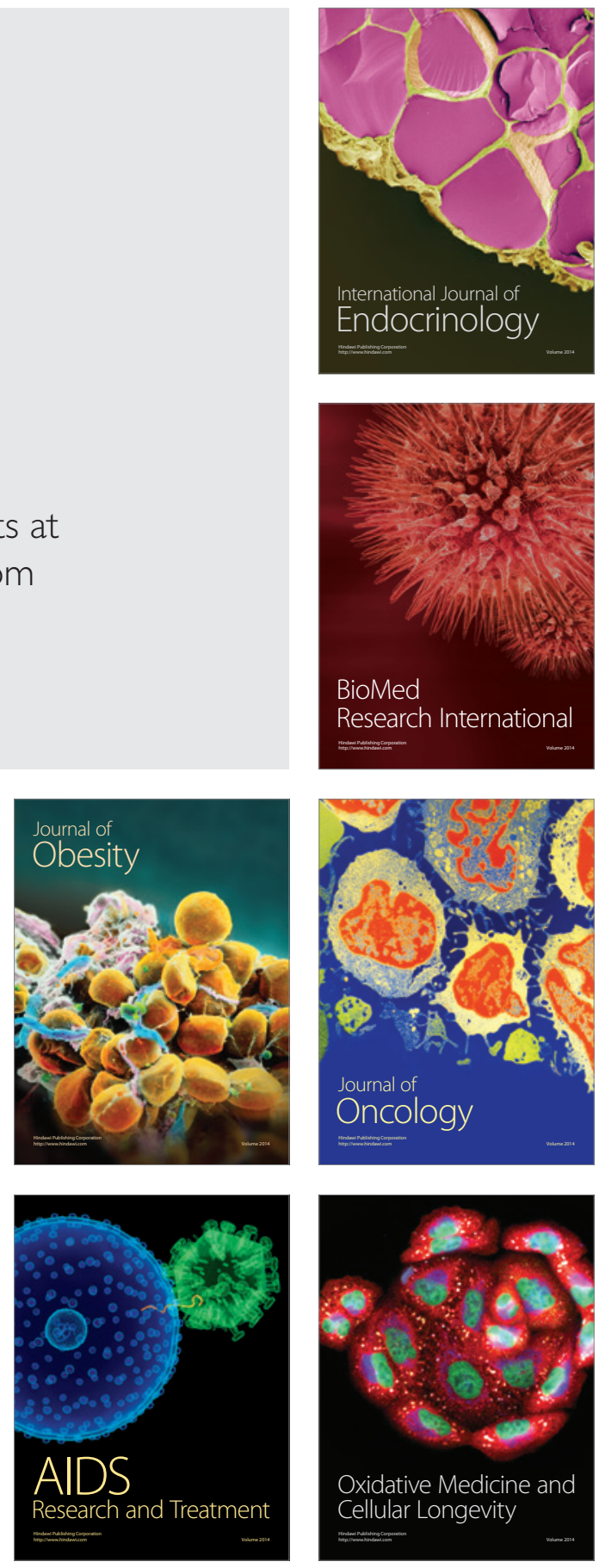